\title{
Assessment of role of eosinophils in the progression of tongue carcinoma
}

\author{
Kaveri Hallikeri', Swetha Acharya ${ }^{2}$, Shilpa Chatni ${ }^{3}$, Darshika Gandhi ${ }^{4}$, B R Patil ${ }^{5}$ \\ ${ }^{1}$ Professor, ${ }^{2}$ Associate Professor, ${ }^{4}$ Post Graduate Student, Department of Oral and Maxillofacial Pathology, SDM College \\ of Dental Sciences and Hospital, Dharwad, ${ }^{3}$ Consultant Head and Neck Surgical Oncology, ${ }^{5}$ Professor and Head, \\ Department of Oncosurgery, Karnataka Cancer Therapy and Research Center, Navnagar, Hubli, Karnataka, India
}

Background: Tumor associated tissue eosinophilia (TATE) is known as stromal infiltration of eosinophils in the stroma of tumor not associated with tumor necrosis or ulceration. It has been described in a variety of neoplasms, but the role in oral squamous cell carcinoma (OSCC) of tongue has not yet been clearly defined. Association of TATE with OSCC has shown variable results ranging from favorable to unfavorable or even no influence on prognosis. Aims and Objectives: The aim of the present study was to correlate TATE with histopathological grades, lymph node status, tumor thickness and nature of tumor cells at the invasive front in OSCC of tongue. Material and Methods: Retrospectively fifty six cases of OSCC of tongue treated with radical neck dissection were included, which were divided into Group I consists 22 cases (lymph node with metastasis) \& Group II consists 34 cases (lymph node without metastasis). H \& E stained sections were used to analyze TATE and compared with histopathological grades, lymph node status, tumor thickness and nature of invasive front. Statistical analysis was done using Chi-square test. Results: TATE did not have any significant association with histopathological grades, lymph node status and nature of tumor cells at invasive front. But, tumor thickness and presence of eosinophils showed significant association. Also as the tumor thickness increased, the cells were more discohesive at the invasive front region. Conclusion: Microenvironment of tumor significantly contributes in the tumor progression. Tumor thickness, nature of tumor cells at the invasive front and TATE together can help in assessing the behavior of tongue squamous cell carcinoma.
http://nepjol.info/index.php/AJMS DOI: 10.3126/ajms.v7i5.15037 E-ISSN: 2091-0576 P-ISSN: 2467-9100

Key words: Eosinophils, Invasive front, Metastasis, Tongue, Tumor thickness

\section{INTRODUCTION}

Oral squamous cell carcinoma has a high possibility for local invasiveness and an increased tendency for cervical lymph node metastasis. Despite exercising clinical staging, histopathological grading and various treatment methods, the overall prognosis of patients has not improved significantly in the past 20 years, with $45-50 \%$ of 5 -year survival rates.Prognostic value of tumor and stromal interactions has been neglected in the past.

Cancer associated stroma is a complex medium where a variety of interactions between tumor and stroma takes place. The stromal elements have prognostic as well as response-predictive information, and abundant target therapy within the tumor microenvironment are being continually evaluated. ${ }^{1}$ Tumor microenvironment is orchestrated by various components including the inflammatory cells, which consists of lymphocytes, plasma cells, neutrophils, macrophages, mast cells and eosinophils. ${ }^{2}$ Most studies have mainly focused on lymphoplasmacytic infiltration; however limited literature is available on the role played by eosinophils in SCC of tongue specifically. Eosinophil infiltration in tumor microenvironment is known as tumor associated tissue eosinophilia (TATE).

Correlation of TATE with prognosis has shown variable results in OSCC. It has been related to a favorable as well as an unfavorable prognosis or even having no influence on patient outcome. ${ }^{1-8}$ Therefore, the aim of this study was 
to determine the presence of TATE in SCC of tongue and to assess if a relationship exists between TATE and histopathological grades, lymph node metastasis, tumor thickness and nature of tumor cells at the invasive front.

\section{MATERIALS AND METHODS}

Fifty six paraffin embedded tissue blocks of histopathologically diagnosed cases of SCC of tongue based on Broder's system of grading, with concomitant neck dissections were retrieved from the archives of the Department of Oral and Maxillofacial Pathology, SDM College of Dental Sciences Dharwad and The Karnataka Cancer Therapy \& Research Institute, Navanagar, Hubballi. The cases were categorized into 2 groups; Group I comprising of 22 cases positive for lymph node metastasis and Group II comprising of 34 cases negative for lymph node metastasis. Study sample consisted of 36 cases of Grade 1, 16 cases of Grade 2, 17 of Grade 3 and 1 case of Grade 4 OSCC. Tumor thickness was measured from the surface till the invasive front region; presence of eosinophils was studied at the invasive front region along with the nature of tumor cells at the invasive front. Chisquare tests were performed to analyze the data.

\section{RESULTS}

The incidence of tongue OSCC in young patients ( $<40 \mathrm{yrs;}$ $34 \%$ ) is relatively low as compared to older age group (>40yrs, 66\%). OSCC was common among males (80\%) than females. The common risk factor noted among these patients was tobacco chewing (57\%) followed by tobacco smoking $(16 \%)$, combined habits (13\%) and 14\% did not have any history of habit. $79 \%$ of patients reported were in the clinicalyl advanced stage III \& IV at the time of diagnosis, where as $21 \%$ were at the clinical stage I \& II (Table 1).

When histopathological parameters were considered, $86 \%$ of cases were well differentiated SCC and 14\% comprised of moderate \& poorly differentiated SCC (Table 2). Nature of invasive front studied showed that $77 \%$ of cases had discohesive or single cells and $23 \%$ had either pushing margin or cohesive cells (Table 3). Histopathologically, $39 \%$ of cases showed metastatic deposit in lymph node and $61 \%$ cases showed only reactive changes in lymph nodes (Table 4). The $77 \%$ of cases had tumor thickness greater than $4 \mathrm{~mm}$ and $23 \%$ of cases less than $4 \mathrm{~mm}$ (Table 5).

Among group I, 7 cases showed the presence of eosinophils and absence in 15 cases, whereas in group II, 15 cases had eosinophils and 19 cases did not reveal eosinophils. The presence or absence of eosinophils

\begin{tabular}{|c|c|c|}
\hline Parameters & Grouping & Number of cases (\%) \\
\hline Age & $\begin{array}{l}<40 \text { yrs } \\
>40 \text { yrs }\end{array}$ & $\begin{array}{l}19(34) \\
37(66)\end{array}$ \\
\hline Gender & $\begin{array}{l}\text { Male } \\
\text { Female }\end{array}$ & $\begin{array}{l}45(80) \\
11(20)\end{array}$ \\
\hline Habit & $\begin{array}{l}\text { Tobacco chewing } \\
\text { Tobacco smoking } \\
\text { Combined } \\
\text { No habit }\end{array}$ & $\begin{array}{l}32(57) \\
9(16) \\
7(13) \\
8(14)\end{array}$ \\
\hline Stage & $\begin{array}{l}\mathrm{I}+\mathrm{II} \\
\mathrm{III}+\mathrm{IV}\end{array}$ & $\begin{array}{l}12(21) \\
44(79)\end{array}$ \\
\hline
\end{tabular}

\begin{tabular}{|c|c|c|c|c|}
\hline \multirow{2}{*}{$\begin{array}{l}\text { Tumor grading of } \\
\text { SCC of tongue }\end{array}$} & \multicolumn{2}{|c|}{ Eosinophils } & \multirow{2}{*}{$\begin{array}{l}\text { Total } \\
(\%)\end{array}$} & \multirow[t]{2}{*}{ p-value } \\
\hline & Absent & Present & & \\
\hline Well-differentiated & 31 & 17 & $48(86)$ & 0.146 \\
\hline $\begin{array}{l}\text { Moderately \& poorly } \\
\text { differentiated }\end{array}$ & 3 & 5 & $8(14)$ & \\
\hline Total & 34 & 22 & 56 & \\
\hline
\end{tabular}

\begin{tabular}{|c|c|c|c|c|}
\hline \multirow{2}{*}{$\begin{array}{l}\text { Nature of tumor } \\
\text { invasive front }\end{array}$} & \multicolumn{2}{|c|}{ Eosinophils } & \multirow{2}{*}{$\begin{array}{c}\text { Total } \\
(\%)\end{array}$} & \multirow[t]{2}{*}{$p$-value } \\
\hline & Absent & Present & & \\
\hline 1 & 10 & 3 & $13(23)$ & 0.172 \\
\hline 2 & 24 & 19 & $43(77)$ & \\
\hline Total & 34 & 22 & 56 & \\
\hline
\end{tabular}

1- Cohesive cells in the form of islands, cords and strands, 2- Discohesive cells in the form of groups or single

\begin{tabular}{lcccc} 
Table 4: Correlation between lymph node \\
metastasis and eosinophils \\
\cline { 1 - 3 } $\begin{array}{l}\text { Lymph node } \\
\text { metastasis }\end{array}$ & \multicolumn{2}{c}{ Eosinophils } & $\begin{array}{c}\text { Total } \\
\text { (\%) }\end{array}$ & p-value \\
\cline { 2 - 3 } & Absent & Present & & \\
\hline Group I & 15 & 7 & $22(39)$ & 0.357 \\
Group II & 19 & 15 & $34(61)$ & \\
Total & 34 & 22 & 56 & \\
\hline
\end{tabular}

Group I- Lymph node with metastatic deposit, Group II- Lymph node without metastatic deposit

among the histopathological grading and with or without metastasis to the lymph node did not show any statically significant difference.

Statistical significant difference was evident with tumor thickness and the presence of eosinophils. In the tumor thickness with less than $4 \mathrm{~mm}$ only 2 cases $(2 / 13)$ showed the presence of eosinophils while 11 cases did not show the evidence of eosinophils. But as the tumor thickness increased $(>4 \mathrm{~mm}), 20$ out of 43 cases showed the presence of eosinophils. 


\begin{tabular}{|c|c|c|c|c|}
\hline \multirow{2}{*}{$\begin{array}{l}\text { Tumor } \\
\text { thickness }\end{array}$} & \multicolumn{2}{|c|}{ Eosinophils } & \multirow{2}{*}{$\begin{array}{l}\text { Total } \\
(\%)\end{array}$} & \multirow[t]{2}{*}{ p-value } \\
\hline & Absent & Present & & \\
\hline$<4 \mathrm{~mm}$ & 11 & 2 & $13(23)$ & 0.044 \\
\hline$>4 \mathrm{~mm}$ & 23 & 20 & $43(77)$ & \\
\hline Total & 34 & 22 & 56 & \\
\hline
\end{tabular}

\begin{tabular}{|c|c|c|c|c|}
\hline \multirow{2}{*}{$\begin{array}{l}\text { Tumor } \\
\text { thickness }\end{array}$} & \multicolumn{2}{|c|}{ Nature of invasive front } & \multirow{2}{*}{$\begin{array}{c}\text { Total } \\
\text { (\%) }\end{array}$} & \multirow[t]{2}{*}{ p-value } \\
\hline & 1 & 2 & & \\
\hline$<4 \mathrm{~mm}$ & 4 & 9 & $13(23)$ & 0.786 \\
\hline$>4 \mathrm{~mm}$ & 9 & 34 & $43(77)$ & \\
\hline Total & 13 & 43 & 56 & \\
\hline
\end{tabular}

Also, as the tumor thickness increased the cells were more discohesive at the invasive front region and statistically correlated with the eosinophils in the stroma (Table 6). Eosinophils and its relation with nature of tumor cells at the invasive front revealed $19(19 / 43)$ cases showed presence of eosinophils in the presence of discohesive, isolated tumor cells. Whereas only 3 cases $(3 / 13)$ revealed the presence of eosinophils with the cohesive nature of tumor cells at the invasive front region.

\section{DISCUSSION}

Eosinophils function as key mediators in host defense primarily against various infections; its role in allergic diseases like asthma, atopic dermatitis, gastrointestinal disorders and hyper eosinophilic diseases is not destructive but mediates the pathology. Tissue eosinophils have been recognized in cancer for almost 120 years. Their role has been implicated in the carcinoma of esophagus, gastrointestinal tract, uterine, cervical, skin and oral cavity. ${ }^{9}{ }^{-13}$ Tumor associated tissue eosinophilia (TATE) was first described by Przewoski in 1896 in cervical carcinoma, characterized by presence of peritumoral and intratumoral eosinophil infiltrate. The evidence showing that eosinophils infiltrate into tumor sites suggests that they play a role in host tumor interactions.

The relationship between inflammation and cancer is more widely accepted; however, many of the molecular and cellular mechanisms mediating this relationship remain unresolved. Inflammatory cell infiltration around the tumor, especially at the sites of frank invasion, has been considered to play an important role in the biological behavior of tongue SCC. ${ }^{14}$ Most of the studies performed OSCC \& TATE are from all different subsites. This could be one of the reasons for the variation in the prognostic value ranging from good to poor to no prognostic correlation.

Emphasizing the fact that OSCC is a heterogeneous group of tumor, TATE should be analyzed based on the subsites. Tongue carcinoma is commonest and its behavior is different from the other sites. Also, there is an increased incidence of tongue CA in young people with over-representation of female. Recently, attention has been directed to the infiltration of TATE in tongue SCC. But the role of TATE, their prognostic value in tongue SCC still remains ambiguous.

Our study is an attempt to understand the role of TATE in tongue SCC at the invasive front. To the best of our knowledge, this is the first study to correlate TATE with histopathological grades, lymph node status, tumor thickness and nature of tumor cells at the invasive front in a large sample size.

Till date there is no universally accepted method for quantification and grading of TATE and this has led to conflicting results. Various methods used are mean values of TATE to grade them into low, moderate and heavy, density of TATE at the invasive front and rest of the tumor area, peritumoral and intratumoral areas, number of eosinophils per high power; different sample size and different method of eosinophils staining could result in variation in the result. ${ }^{3,7}$

Eosinophils have protective role against epithelial tumor by releasing cytotoxic proteins like eosinophil peroxidase, major basic protein, eosinophil cationic protein, etc. and also by activating the immune system resulting in a better prognosis. Inhibiting the immune system, eosinophils play a role in promoting epithelial tumor growth, thus causing poor prognosis. ${ }^{15}$

Histopathological grading of tumor is done based on the differentiation of cells as well, moderate and poorly differentiated and is a standard method to assess the behavior of the tumor. In the present study, we did not get the significant correlation between TATE and histopathological grades of tongue SCC. Our findings are in accordance with a study in which no correlation was found between TATE and histopathological grading., ${ }^{8,16}$

Alkhabuli and High did not find correlation between density of eosinophils and SCC differentiation. Similar, finding has been recorded by Tadbir et al. and Rahrotaban et al., but it was lower in poorly differentiated group. ${ }^{8,17}$ According to Jain $\mathrm{M}$ et al., non-metastatic group with well and moderately differentiated tumor had higher 
mean eosinophilic count than metastatic group. In the metastatic group, well differentiated carcinoma had higher TATE count than moderately differentiated. ${ }^{2}$ Iwaski et al. found that low degree of tumor cell differentiation was significantly associated with strong eosinophilic infiltration, thus suggesting that particular level of differentiation of carcinoma preferentially attract eosinophils into the site of lesion. ${ }^{10}$

Cervical lymph node metastasis is an important prognostic factor in OSCC. In studies by Jain M and Goldsmith et al., there was a significant increase in eosinophil counts in non-metastatic carcinoma than metastatic oral carcinoma. ${ }^{2,3}$ Falconieri et al. also confirmed the eosinophil-rich squamous cell carcinoma, although associated with metastatic involvement of cervical lymph node, showed less aggressive behavior as compared to ordinary SCC. ${ }^{4}$ Therefore, eosinophilia can be a favorable histopathological prognostic factor. But in the present study, in the presence of eosinophils, only $7(7 / 22)$ cases showed the lymph node involvement and $15(15 / 34)$ cases developed lymph node metastasis but did not show any statistical significant difference between the eosinophils with the lymph node involvement. Similarly, Alrawi et al. demonstrated that patients with high eosinophil indices had a statistically lower survival than those with lower eosinophil indices. ${ }^{18}$ Alkhabuli and High found significant correlation between eosinophil density and survival and lymph node metastasis. ${ }^{16}$ Oliveira D T et al. demonstrated the intense eosinophilic infiltration can be a significant feature to predict occult lymph node metastasis in early OSCC patients. ${ }^{19}$ Eosinophils at the primary or secondary metastatic site how do they migrate are explained by Lorena SC et al., ${ }^{20}$ The factors stimulating local migration of eosinophils are released by the tumor tissue i.e. chemotactic factors such as eotaxin has selective action on eosinophils - play a role in in-situ eosinophilic infiltration and maintenance. ${ }^{20}$ Also, PGD2 derived and secreted by oral carcinoma play an important role via CRTH2 in eosinophil recruitment and subsequent antitumor activity through the action of eosinophilic cationic proteins. ${ }^{21}$

Ocular micrometer is used to measure tumor thickness by recording the measurements from the superficial granular layer of the tumor epithelium to the tumor cells at the deepest part of the invasive front. It was suggested that the tumor thickness greater than $5 \mathrm{~mm}$ of tumor depth showed probable cervical lymph node metastasis. The metastatic rate of $64.7 \%$ was found in the group of more than $5 \mathrm{~mm}$ of tumor depth. In contrast, only $5.9 \%$ cervical lymph node metastasis was observed with less than $5 \mathrm{~mm}$ of depth of invasion. ${ }^{22}$ This is supported by the fact that as the depth of tumor invasion increases, the presence of lymphatic channels in the deeper connective tissue has a high propensity for cervical metastasis.

In the present study with tumor thickness greater than $4 \mathrm{~mm}, 19$ cases (19/43) showed metastasis to the lymph node, tumor thickness with less than $4 \mathrm{~mm}$, only 3 cases $(3 / 13)$ showed metastasis. The role of eosinophils in the progression of tumor is by the release of chemical mediators. The presence of eosinophils was seen in 2 cases and 11 cases did not show the evidence of eosinophils with the tumor thickness less than $4 \mathrm{~mm}$. But as the tumor thickness increased ( $>4 \mathrm{~mm}$ ), 20 cases showed the presence of eosinophils and 23 cases did not show the evidence of eosinophils. The tumor thickness and eosinophils showed statistical significant difference.

Also as the tumor thickness increased, the cells were more discohesive at the invasive front region and statistically correlated with the eosinophils in the stroma. Invasive part of the tumor has their morphological and functional characteristics compared to rest of the tumor and dictates the biological aggressiveness of OSCC. Pattern of invasion at the invasive site is described as pushing, well delineated infiltrating borders to discohesive small groups.

There was significant correlation with eosinophils and nature of tumor cells at the invasive front. In situ hybridization study revealed eosinophils have the capacity to synthesize actively 92-kd gelatinase, which degrade the basement membrane and extracellular matrix which enhances the tumor invasion and increase in the tumor thickness. ${ }^{23}$

\section{CONCLUSION}

Focus from epithelial changes has begun to change towards the microenvironment of the tumor, which significantly contribute in the tumor development. However, ambiguity still exists with respect to TATE and their exact role in prognosis of OSCC.

Tumor thickness, nature of tumor cells at the invasive front and TATE together can help in assessing the behavior of tongue squamous cell carcinoma. TATE can be considered as an important microscopic parameter during histopathological reporting.

\section{REFERENCES}

1. Woolgar JA. Histopathological prognosticators in oral and oropharyngeal squamous cell carcinoma. Oral Oncol 2006; 42: 229-239.

2. Jain M, Kasetty S, Sudheendra US, Tijare M, Khan S and Desai A. Assessment of tissue eosinophilia as a prognosticator 
in oral epithelial dysplasia and oral squamous cell carcinoma-An image analysis study. Pathol Res Int 2014; 507-512.

3. Goldsmith MM, Cresson DH, and Askin FB. Part II. The prognosticator significance of stromal eosinophilia in head \& neck cancer. Otolaryngol Head \& Neck Surg 1987; 96: 319-324.

4. Falconieri G, Luna MA, Pizzalitto S, DeMagalio G, Angione $V$ and Rocco M. Eosinophil -rich squamous cell carcinoma of oral cavity: A study of 13 cases and delineation of a possible new microscopic entity. Annals of Diagnostic Pathology 2008; 12: 322-327.

5. Brandwein-Gensleir M, Smith RV, Wang B, Penner C, Theilken A, Broughel $D$, et al. Validation of the histologic risk model in a new cohort of patients with head and neck squamous cell carcinoma. Am J Surg Pathol 2010; 34: 676-688.

6. Chatzistamou I, Rodriguez J, Jouffroy T, Girod A, Point D, Sklavounou $A$, et al. Prognostic significance of tumor shape and stromal chronic inflammatory cell infiltrate in squamous cell carcinomas of the oral tongue. J Oral Path Med 2010; 39: 667-671.

7. Dorta RG, Landman G, Kowaslki LP, Lauris JRP, Latorre MRDO and Oliviera DT. Tumor associated tissue eosinophilia as a prognostic factor in squamous cell carcinoma. Histopathology 2002; 41: 152-157.

8. Tadbir AA, Ashraf MJ and Sardari Y. Prognostic significance of stromal Eosinophilic infilteration in oral squamous cell carcinoma. J Craniofac Surg 2009; 20: 152-157.

9. Ohashi Y, Ishibashi S, Suzuki T, Shineha R, Moriya T, Satomi S, et al. Significance of tumor associated tissue eosinophilia and other inflammatory cell infiltrate in early esophageal squamous cell carcinoma. Anticancer Research 2000; 20: 3025-3030.

10. Iwasaki $\mathrm{K}$, Torisu $\mathrm{M}$ and Fujimura $\mathrm{T}$. Malignant tumor and eosinophils I. Prognostic significance in gastric cancer. Cancer 1986; 58: 1321-1327.

11. Lowe $D$ and Fletcher CDM. Eosinophilia in squamous cel carcinoma of the oral cavity, external genitalia and anus- Clinical correlations. Histopathology 1984; 8: 627-632.

12. VanDriel WJ, Hogendoorn PCW, Jansen FW, Zwinderman AH, Trimbos JB and Fleuren GJ. Tumor-associated eosinophilic infiltrate of cervical cancer is indicative for a less effective immune response. Human Pathology 1996; 27: 904-911.

13. Lowe D, Fletcher CDM, Shaw MP and McKee PH. Eosinophil infiltration in keratoacanthoma and squamous cell carcinoma of the skin. Histopathology 1984; 8: 619-625.

14. Lundqvist L, Stenlund H, Laurell $G$ and Nylander K. The importance of stromal inflammation in squamous cell carcinoma of the tongue. J Oral Pathol Med 2012; 41: 379-383.

15. Martinelli-Klay CP, Mendis BRRN and Lombardi T. Eosinophils and oral squamous cell carcinoma: A short review. Journal of Oral Oncol 2009; 2009:310132.

16. Alkabuli JO and High AS. Significance of eosinophil counting in tumor associated tissue eosinophilia (TATE). Oral Oncol 2006; 42: 849-850.

17. Rahrotaban $\mathrm{S}$, Khatibi $\mathrm{A}$ and Allami A. Assessment of tissue eosinophilia in head \& neck carcinoma by Luna staining. Oral Oncol 2011; 47: 74-79.

18. Alrawi SJ, Tan D, Stoler DL, Dayton M, Anderson GR, Mojica P, et al. Tissue Eosinophilic infiltration: A useful marker for assessing stromal invasion, survival and locoregional recurrence in head and neck neoplasia. Cancer J 2005; 11(3): 217-225.

19. Oliveira DT, Biassi TP, Faustino SES, Carvalho AL, Landman $G$ and Kowalski LP. Eosinophils may predict occult lymph node metastasis in early oral cancer. Clin Oral Invest 2012; 16: $1523-1528$.

20. Lorena SC, Oliveira DT, Dorta RG, Landman G and Kowalski LP. Eotaxin expression in oral squamous cell carcinomas with and without tumor associated tissue eosinophilia. Oral Dis 2003; 9(6): 279-283.

21. Davoine F, Sim A, Tang C, Fisher S, Ethier C, Puttagunta L, et al Eosinophils in human oral squamous cell carcinoma; role of prostaglandin D2. J of Inflammation 2013; 10: 4-10.

22. Woolgar JA. T2 carcinoma of the tongue: The histopathologist's perspective. Br J Oral Maxillofac Surg 1999; 37: 187-193.

23. Stah- Backdahlle $M$ and Parks CW. 92-kd gelatinase is actively expressed by eosinophils and stored by neutrophils in squamous cell carcinoma. Am J Pathol 1993; 142: 995-1000.

\section{Authors Contribution:}

KH - Concept and design of the study, reviewed the literature, manuscript preparation and critical revision of the manuscript; SA - Conceptualized study, literature search, statistically analyzed and interpreted, prepared first draft of manuscript and critical revision of the manuscript; SC - Concept of study, collected data and review of study; DG - Literature search, statistically analyzed and interpreted, prepared first draft of manuscript; BRP - Conceptualized study, literature search, statistically analyzed and interpreted.

Source of Support: Nil, Conflict of Interest: None declared. 